\title{
O processo de morrer e a morte no enfoque dos profissionais de enfermagem de UTIs
}

\author{
DYING AND DEATH SEEN BY INTENSIVE CARE UNIT NURSING PROFESSIONALS
}

EL PROCESO DE MORIR Y LA MUERTE EN EL ENFOQUE DE LOS PROFESIONALES DE ENFERMERÍA DE UCIS

\section{Beatriz Aparecida Ozello Gutierrez', Maria Helena Trench Ciampone"}

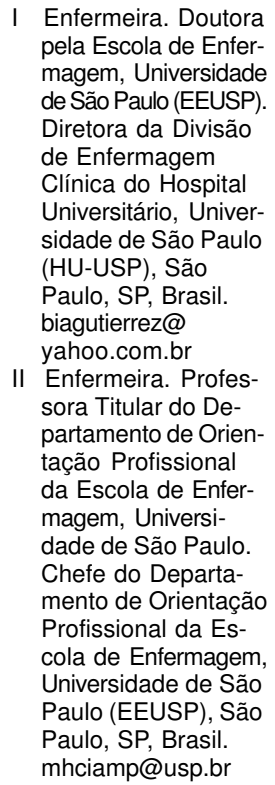
pela Escola de Enfermagem, Universidade de São Paulo (EEUSP). Diretora da Divisão de Enfermagem Clínica do Hospital Universitário, Universidade de São Paulo (HU-USP), São Paulo, SP, Brasil. biagutierrez@ yahoo.com.br

II Enfermeira. Professora Titular do Departamento de Orientação Profissional da Escola de Enfermagem, Universidade de São Paulo. Chefe do Departamento de Orientação Profissional da Escola de Enfermagem, Universidade de São Paulo (EEUSP), São Paulo, SP, Brasil. mhciamp@usp.br

\section{RESUMO}

Em relação ao processo de morrer e a morte, cada sociedade tem sua própria cultura, hábitos, crenças e valores, que a aproxima ou a diferencia de outras, oferece aos indivíduos uma orientação de como devem se comportar e o que devem ou não fazer diante desse fato. O objetivo deste estudo foi identificar as concepções culturais relacionadas ao processo de morrer e à morte no contexto de trabalho dos profissionais de enfermagem de UTIs. Os dados foram coletados por meio de entrevistas individuais e grupo focal e analisados segundo técnicas qualitativas. As narrativas mostram múltiplas dimensões determinantes das atitudes e ações profissionais, que vão além do conhecimento técnico. Fica evidente que esses profissionais procuram refúgio nas suas crenças e valores para suportar um trabalho que lhes impõe tantas cargas.
\end{abstract}

\section{DESCRITORES}

Atitude frente a morte.

Morte.

Unidades de Terapia Intensiva. Equipe de enfermagem.

\section{ABSTRACT}

When it comes to dying and death each society has its own culture, habits, beliefs and values, which brings it closer to or draws it apart from others and gives its members guidance as to how they should behave and what they should or should not do in the face of them. The goal of this study was to identify the cultural conceptions regarding dying and death in the working context of Intensive Care Units (ICU) nursing professionals. The data were collected through individual interviews and a focal group and analyzed using qualitative techniques. The narratives show multiple determinant dimensions of the professional attitudes and actions that go beyond technical knowledge. It is evident that these professionals look for refuge in their beliefs and values in order to put up with such a burdensome work.

\section{KEY WORDS}

Attitude to death.

Death.

Intensive Care Units.

Nursing team.

\section{RESUMEN}

En relación al proceso de morir y la muerte, cada sociedad tiene su propia cultura, hábitos, creencias y valores, que la aproxima o la diferencia de otras, ofrece a los individuos una orientación de cómo deben comportarse y lo que deben o no hacer delante de ese hecho. El objetivo de este estudio fue identificar las concepciones culturales relacionadas al proceso de morir y a la muerte en el contexto de trabajo de los profesionales de enfermería de las Unidades de Cuidados Intensivos (UCIs). Los datos fueron colectados por medio de entrevistas individuales y grupo focal y analizados según técnicas cualitativas. Las narrativas muestran múltiplas dimensiones determinantes de las actitudes y acciones profesionales, que van a más allá del conocimiento técnico. Queda evidente que esos profesionales buscan refugio en sus creencias y valores para soportar un trabajo que les impone tantas cargas.

\section{DESCRIPTORES}

Actitud frente a la muerte.

Muerte.

Unidades de Terapia Intensiva. Grupo de enfermería. 


\section{INTRODUCÃO}

Estudar as concepções culturais do processo saúde-doença-morte nas diferentes sociedades podem possibilitar aos profissionais de enfermagem compreenderem seus próprios valores e crenças diante do processo de morrer e da morte bem como suas atitudes e ações relacionadas com as questões do cotidiano que influenciam a sua vida pessoal e profissional.

Nesse sentido, ao discutir a respeito de cultura, é necessário ter em mente a humanidade em toda a sua riqueza e multiplicidade de formas de existência e expressões, pois só assim conseguiremos compreender a complexidade que há nos agrupamentos humanos e as características que os unem e diferenciam. Cada realidade cultural tem a sua lógica interna, por isso é relevante conhecê-la para atribuir sentido às suas práticas, costumes, concepções e as transformações pelas quais estas passam, ou seja, é fundamental estabelecer a variedade de procedimentos culturais com os contextos em que esses são produzidos. Assim, o estudo da cultura contribui com o combate a preconceitos, proporcionando base sólida para que haja respeito e dignidade nas relações humanas ${ }^{(1)}$.

Partindo da premissa de que o homem é um ser social, que a doença é encarada de várias formas: ora como um problema físico ou mental, ora como um problema biológico ou psicossocial fica evidente que, poucas vezes, a doença é encarada como um fenômeno multidimensional. Para tanto, a antropologia, enquanto ciência que estuda a história natural e cultural do homem e dos grupos humanos contribui para a construção de novos paradigmas para a abordagem dos processos saúde e doença( ${ }^{(2)}$.

A saúde não se caracteriza negativamente pela ausência de doenças, mas é um estado de completo bem-estar físico, mental e social. No entanto, este conceito é bastante controverso e passivo de muitas críticas, exigindo atenção e estudos meticulosos.

Neste ponto, a Organização Panamericana de Saúde considera a saúde um processo resultante da interação de um conjunto de fatores que determinam e influenciam a condição de viver e a qualidade de vida, portanto, trata-se de um aspecto que contribui para formar o capital social. Constitui a capacidade da população de desenvolver potencialidades pessoais para realizar aspirações, satisfazer necessidades, vencer os desafios e encontrar alternativas de vida ${ }^{(3)}$.

Vários especialistas, ao definirem o que é doença, classificaram-na como um evento biológico ou evento individual, atrelando-a a um evento oriundo de alterações anatômicas, fisiológicas ou bioquímicas, sendo que, em alguns casos, es- sas alterações podem ser mistas, isto é, mais de uma alteração pode estar presente. Contudo, de modo mais amplo, a doença pode ser considerada um evento humano, quando está ligada a uma série de desconfortos ou desajustes psicológicos, provocados pela interação entre pessoas e ambiente em que vivem, que podem provocar desajustes ao bem-estar ${ }^{(4)}$.

Como profissionais da saúde, sabemos que o surgimento de uma doença grave, sem probabilidades de cura, consiste em situação problemática que mobiliza psico-sócio-espiritualmente o sujeito para enfrentá-la, sendo que esse processo desencadeia uma mobilização na família e/ou em outras pessoas com quem o doente mantém relacionamentos significativos.

Outro aspecto que observado é que mediante a iminência da morte, esta provoca nos indivíduos reações diferentes constituindo-se num complexo processo. Alguns se retraem e vivenciam o medo, outros, porém, começam a valorizar o tempo que ainda dispõem e passam a enxergar a vida de maneira mais plena o que favorece uma adaptação.

Nesse sentido, os profissionais de saúde devem criar possibilidades para que o indivíduo compreenda a sua doença, ao invés de focalizar somente a sua saúde, pois essa conscientização pode ajudá-lo a enfrentar a enfermidade, e até mesmo facilitar a conscientização da aproximação da sua morte.

A visão relacionada ao ato de morrer tem se modificado com o decorrer do processo de transformação das sociedades, e está diretamente ligado ao estágio de desenvolvimento dessa sociedade, assim como as suas especificidades, valores e ritos ${ }^{(5)}$.

Cabe destacar que, em relação à morte e ao processo de morrer, cada sociedade tem seus próprios comportamentos, hábitos, crenças e atitudes, que oferecem aos indivíduos uma orientação de como devem se comportar e o que devem ou não fazer, refletindo a cultura própria de cada região e, também, diferenciando-a de outros.

Na cultura ocidental, cada vez mais a morte é escondida, pois é considerada um momento de fragilidade e vergonha; portanto, deve acontecer em silêncio para não incomodar ninguém. Como resultado, a grande maioria das pessoas, quando indagadas a respeito, sonham com a boa morte, em geral, morrer dormindo, pois assim não sentirão a morte e não incomodarão ninguém.

O agravante, na nossa cultura, é que os profissionais de saúde, dentre esses os de enfermagem, estão despreparados para lidar com as questões relacionadas à morte e ao processo de morrer. Este tende a ser considerado um assunto menos importante nas instituições de saúde, pois a imagem do hospital é vinculada a um local de cura, e todos que o procuram têm a esperança de sair de lá curados. 
Contudo, a doença deve ser enfrentada como experiência humana, representando um processo contínuo de aprendizado e crescimento, no qual o paciente, família e profissionais de saúde necessitam adequar seus comportamentos, sempre que isto for necessário, visando uma melhor qualidade de vida.

Para tanto, acreditamos que a realidade cultural dos profissionais obedece a uma lógica interna, e que é necessário conhecê-la para atribuir sentido aos costumes, práticas e concepções e, desse modo, operar transformações nas quais tal lógica está inserida, de modo a ampliar o leque de possibilidades de tratamentos, para além dos convencionais.

Esse enfoque deve ser buscado na formação dos profissionais de saúde, traduzindo-se em novos conhecimentos e habilidades e fortalecendo o compromisso social desses profissionais com práticas de uma clínica ampliada, pois não restritas à obstinação da cura.

Partindo da premissa que a realidade cultural dos profissionais de enfermagem que atuam em UTI obedecem a uma lógica interna, imprimindo um diferencial em suas ações ao assitir pacientes em processo de morte, é que esse estudo foi desenvolvido.

\section{OBJETIVO}

Identificar as concepções culturais relacionadas ao processo de morrer e à morte no contexto dos profissionais de enfermagem de UTI.

\section{MÉTODO}

Nesse processo investigativo optamos pela abordagem qualitativa, por julgarmos que a mesma permite acessar representações e desvelar valores que permeiam as práticas profissionais da equipe de enfermagem ao assistir pacientes em processo de morte. Nesse tipo de abordagem o próprio ambiente e os sujeitos que vivenciam o fenômeno, constituem-se como fonte viva de dados. Para tanto, utilizamos uma combinação de técnicas de coleta e de análise qualitativa de dados que constituem-se em recursos importantes para se alcançar o objetivo proposto ${ }^{(6)}$. Dentre essas a entrevista em profundidade e o grupo focal combinado com estratégias de oficinas.

\section{Local de estudo}

O presente estudo foi desenvolvido no Hospital Universitário da Universidade de São Paulo (HU-USP) após aprovação da pesquisa pelo Comitê de Ética e Pesquisa do HU-USP.

Elegemos como cenário de estudo, especificamente as Unidades de Terapia Intensiva (UTI), de Adulto (UTIA) e Pediátrica (UTI Ped), por serem as áreas onde os profissio- nais de enfermagem se deparam cotidianamente em seu processo de trabalho com o sofrimento dos pacientes e familiares no enfrentamento do processo de morrer, visto que pelas características dessas unidades, os pacientes apresentam quadros graves e muitas vezes irreversíveis.

\section{Os sujeitos da pesquisa}

Foram sujeitos deste estudo as enfermeiras, técnicos e auxiliares de enfermagem que trabalham nessas UTIs. Assim sendo, partimos da hipótese que esses profissionais se deparam com o impacto direto do enfrentamento do processo de morrer e da morte e portanto poderiam ser considerados informantes.

Inicialmente, estes foram convidados a participar do estudo tendo sido solicitado autorização aos sujeitos por meio do Termo de Consentimento Livre e Esclarecido explicando que nos dois momentos, nas entrevistas e nos encontros grupos grupais seria feita a gravação e que apesar disso estaríamos garantindo o anonimato (Parecer CEP n. 251/02).

\section{Coleta de dados}

Os dados foram coletados no primeiro momento por meio de entrevistas semi-estruturadas com o intuito de favorecer a livre expressão dos sujeitos e estimular a abordagem da temática em estudo. As entrevistas foram gravadas e posteriormente transcritas na íntegra e analisadas segundo a técnica da análise de conteúdo, na modalidade de análise temática ${ }^{(6)}$.

A segunda etapa da pesquisa constou da realização de cinco sessões de grupo focal, que tiveram como questões disparadoras a devolutiva dos conteúdos que emergiram da análise do conjunto das nove entrevistas individuais.

A técnica de pesquisa do grupo focal pode ser utilizada no entendimento de como se formam as diferentes percepções e atitudes acerca de um fato ${ }^{(7)}$. Além disso, esta técnica pode enriquecer e ampliar a perspectiva de compreensão em uma pesquisa, assim como possibilitar intervenções transformadoras, que contribuam para uma assistência mais humana e efetiva ${ }^{(8)}$.

\section{Análise dos dados}

O material decorrente das entrevistas individuais e dos cinco encontros constituiu-se no corpus da pesquisa possibilitando apreender opiniões, atitudes, valores e crenças dos indivíduos acerca de diversas questões vivenciadas no cotidiano. Cabe ressaltar que o senso comum elabora, comunica e partilha diversas representações sobre a morte e o processo de morrer, inclusive quando ocorrem longe do contexto domiciliar, como nas UTIs.

A análise temática consiste em desvendar os núcleos de sentidos contidos nas comunicações, cuja presença ou fre- 
qüência tem algum significado importante para os sujeitos que vivenciam determinadas circunstâncias presentes no seu dia-a-dia ${ }^{(6)}$.

Assim, a análise pautou-se no processo de trabalho dos profissionais de enfermagem, visualizando-se como finalidade compreender e intervir nas bases teóricas, filosóficas e históricas do saber e do fazer prático, que norteiam esses profissionais, na difícil tarefa de conviver cotidianamente com a morte e o processo de morrer nas UTIs.

O material resultante das entrevistas individuais e dos grupos focais foi analisado em duas fases: na primeira, uma pré-análise, inicialmente realizamos uma leitura flutuante do material, até atingir uma impregnação desse conteúdo. Na segunda fase, exploração do material, recortamos os dados e os compilamos de acordo com os conteúdos, a partir das unidades de significado. O material produzido nos grupos além de ter passado pelo mesmo processo, foi apresentado em forma de crônicas, onde as pesquisadoras e observadora do grupo entrelaçaram suas interpretações sobre o processo grupal.

A análise das representações dos participantes, resultado do material empírico, foi realizada mediante referencial teórico estruturado nas categorias de saúde-doença-morte e nos aspectos transculturais.

\section{APRESENTAÇÃO E DISCUSSÃO DOS RESULTADOS}

Visualizando que em nossa sociedade o trabalho está fragmentado pela especialização, burocratização, tendendo ao mecanicismo, impregnado por normas e rotinas, centrado em exigências às vezes obsoletas ou exageradas que, muitas vezes, impedem o homem de se transformar e de recriar suas atividades profissionais, é importante apreender e compreender os valores subjacentes às diferentes representações dos profissionais de enfermagem sobre o processo de morrer e da morte com o objetivo de resgatá-las e integrá-las ao modo de ser, pensar, sentir e agir que conferem significado à sua atuação profissional.

\section{Significados sobre o processo de morrer e a morte}

As manifestações do grupo indicam que os participantes, ao pensar no tema sobre a morte e o processo de morrer, baseiam-se nos seus princípios religiosos, fator que permeou a postura dos participantes, várias vezes, durante os nossos encontros. Eles destacaram que, no dia-a-dia de trabalho, freqüentemente apegam-se à religião no momento em que se agrava o estado de um doente e também na proximidade da morte. Notamos que esses princípios religiosos influenciam a maneira desses profissionais aceitarem a morte, pois eles revelaram que a religião conforta-os e os ajuda a suportar melhor o difícil momento que é o final de vida.
Independentemente das diferentes interpretações vinculadas a diversas religiões, todas consideram bastante valioso o apoio espiritual dado ao paciente em processo de morrer. Ao falarmos sobre a religião do paciente e de seus familiares a resposta foi unânime:

\section{Eu respeito a religião deles!!! (Gustavo).}

A fé representa uma das fontes de ajuda mais solicitadas pelos pacientes. Assim, a presença de um religioso, que aborda o significado da vida e da morte segundo as necessidades e desejos dos pacientes, é considerada por esses um gesto de amor e compreensão $0^{(9)}$.

Os depoimentos a seguir, relativos ao batismo de crianças gravemente enfermas e à oração oferecida aos pacientes, comumente praticados pela equipe de enfermagem, de maioria cristã, mostram que ao deparar-se com pacientes gravemente enfermos buscam apoio na sua religião.

Eu batizo muitas crianças. As próprias mães me chamam para eu batizar! (Regina).

A gente reza por ele (Angélica).

A religião ancora o poder de nossos recursos simbólicos para a formulação de idéias analíticas, e esses símbolos religiosos oferecem uma garantia cósmica com o intuito de compreender o mundo e definir os sentimentos e as emoções para suportá-los ${ }^{(10)}$.

As equipes de enfermagem das UTIs do HU-USP respeitam a crença religiosa do paciente e de seus familiares, assim, freqüentemente autorizam a presença de objetos, símbolos, como imagens de santos, medalhas, folhetos com oração ou Bíblia na mesa de cabeceira do paciente. Estes pertences são trazidos, geralmente, pelos familiares do paciente internado nessas unidades.

Eu pergunto para a pessoa de que religião ela é, pois assim, eu sei se o que eu for falar ela acredita ou não. A gente deixa o santinho, a água benta perto do paciente. Alguns pacientes chamam e pedem para conversar com um religioso, padre ou pastor (Carmelita).

A espiritualidade é algo muito mais amplo do que uma determinada prática religiosa, na sua essência consiste na busca de um sentido maior de transcendência da vida. Já a religião está ligada aos aspectos instituídos de determinadas práticas conforme as tradições culturais dos distintos ritos religiosos ${ }^{(11)}$. A espiritualidade pode ser compreendida como uma dimensão da personalidade que habita e se desenvolve no mais íntimo do ser, identifica-se com o si mesmo, que se integra com os valores culturais em um sistema de crenças, símbolos, visão de mundo e sentido de vida pessoal. E essa dimensão espiritual expressa-se em idéias, sentimentos, atitudes e condutas ${ }^{(12)}$. 
É de fundamental importância que na assistência espiritual se respeite tanto a espiritualidade quanto as crenças religiosas do paciente que está morrendo e também de seus familiares, pois essas crenças têm significados importantes para eles, principalmente diante do processo de morte ${ }^{(13)}$.

Geralmente, os profissionais da equipe de enfermagem, ao conversarem com os familiares dos pacientes internados na UTI, costumam tentar confortá-los por meio das crenças religiosas que fazem sentido para eles. Uma frase bastante utilizada é: Tenha fé em Deus.

A religiosidade representa um contato com o divino, é a maneira como a pessoa se conecta com o que acredita serem forças protetoras ou negativas, em seu cotidiano ${ }^{(14)}$.

Os depoimentos desse estudo indicam que os profissionais de enfermagem buscam na espiritualidade e nas crenças religiosas, subsídios para tentar aliviar o sofrimento dos pacientes e, indiretamente, os seus próprios.

Resultados de pesquisa demonstram que a equipe de enfermagem de terapia intensiva apóia-se nas crenças religiosas para enfrentar as situações consideradas difíceis, na tentativa de amenizar o sofrimento causado pelo contato com a morte ${ }^{(15)}$.

Também na presente investigação, durante as narrativas, alguns dos pesquisados confessaram acreditar na vida após a morte. Apesar de terem suas próprias crenças estes demonstram terem muito respeito em relação à individualidade de cada paciente quanto ao crer ou não na vida após a morte. Esta crença parece trazer algum conforto aos profissionais ao lidar com o paciente em processo de morrer, e também ao pensar na sua própria morte.

Ele vai morrer fisicamente, agora espiritualmente ele vai continuar. Posso contribuir também para que ele não morra! A carne vai morrer, mas o espírito prossegue!! Chega o momento da equipe de enfermagem de ajudar neste sentido, já que ele é um paciente terminal. Dando esperança que ele vai viver do outro lado (Gustavo).

Frequientemente, encontramos referências relativas a sonhos de pacientes terminais, antes do óbito, e também de seus familiares, da passagem do espírito do doente terminal para outro lugar. Estes relatos costumam ser denominados na literatura de experências de quase morte ${ }^{(16)}$.

Assim, a aceitação da morte nas diferentes culturas passa a ser mais tranqüila nos casos em que os quadros pósmorte são construídos a partir de modelos teóricos que acreditam na imaginação vital, e esse conceito é definido como uma capacidade psíquica de visualizar e vivenciar um outro plano da realidade, contemplado além dos cinco sentidos, desprovida de fantasias e alucinação ${ }^{(17)}$.

O fato é que independentemente das diferentes interpretações das diversas correntes religiosas, todas elas consideram bastante valioso o apoio espiritual dado ao paciente em processo de morrer. Para reforçar essa dimensão do cuidado a Associação Médica Mundial na Declaração sobre os Direitos dos Pacientes revisada na 56 Assembéia, realizada em outubro de 2005, em Santiago, Chile ${ }^{(a)}$, diz textualmente: o paciente tem o direito de receber ou recusar o conforto espiritual incluindo a ajuda de um ministro de religião da sua escolha.

Cada profissional tem o seu papel específico ao assistir o paciente. No entanto, a partir do momento em que a morte aproxima-se do indivíduo hospitalizado, é necessário que uma pessoa assuma o papel de auxiliar de passagem, isto é, aquele que permanece ao lado do doente, oferecendo-lhe assistência espiritual, com o intuito de facilitar o seu desligamento da vida e a sua entrada no mundo do desconhecido ${ }^{(18)}$.

Esta função, embora não seja reconhecida formalmente, segundo os sujeitos do estudo, tem ficado a cargo dos profissionais da equipe de enfermagem, principalmente nas UTIs, pois os pacientes internados em unidades críticas geralmente estão isolados de seus familiares e entes queridos e somente acompanhados pela equipe de saúde que os assistem. Nem sempre é viável, em função do tempo, a permanência de um ministro/religioso de referência para a pessoa doente ou seus familiares. Assim, muitas vezes, é a enfermagem que permanece ao lado desses pacientes, cuidando deles. Por isso, freqüentemente são esses profissionais que presenciam o ato de morrer, oferecendo algum suporte espiritual, de acordo com as crenças e valores cultivados quando estes são expressos pelos enfermos.

\section{A morte em diferentes fases da vida}

Os participantes do estudo explicitaram que consideram mais penoso se depararem com a criança em processo de morrer. Eles demonstraram sentimentos de revolta e sofrimento.

Estudo sobre a representação da morte na infância para o médico, demonstra que a maioria tem mais dificuldade para aceitar a morte de crianças, representando a mesma como interrupção de uma vida que não chegou a ser vivida na sua plenitude ${ }^{(19)}$.

Os discursos dos sujeitos pertinentes ao presente estudo demonstram ao discorrerem sobre a morte nas diferentes fases da vida que devemos atrelá-la às concepções sobre a vida, a morte e o processo de morrer, pois os indivíduos são fortemente influenciados pelas suas crenças e valores culturais e religiosos que trazem consigo.

Eu fico pensando... Qual a idade certa para morrer? O adulto tem a sua missão, e a criança não tem? Qual o tempo certo para a pessoa morrer? (Gustavo).

Não tem tempo certo!! (Regina).

(a) Disponível em: http://www.wma.net/e/ (Acesso em: 20 mar. 2006)
O processo de morrer e a morte no enfoque dos profissionais de enfermgem em UTIs Gutierrez BAO, Ciampone MHT 
Em criança é triste! É terrível!!! (Regina).

Ele veio, ele morreu, ele nasceu e deu óbito duas horas depois... Cada um tem uma maneira de pensar na morte e na pós morte!!! Você vai buscar lá dentro... (Gustavo).

Assim, corroboram com a percepção de que a morte é parte da existência humana, do crescimento e desenvolvimento, tanto quanto o nascimento. A morte não é um mal a ser destruído, um inimigo a ser combatido ou uma prisão de onde devemos fugir, mas sim uma parte integrante de nossa vida, que proporciona significado à existência do ser humano. Um significado marcado pelo crescimento, pela paz, luz, força interior, beleza, por sentimentos de amor e ampliação da consciência de si e do mundo. Devemos viver intensamente até o momento da morte, pois ao separarmos o processo do morrer da vida deixamos de viver antes da morte ${ }^{(20)}$.

Alguns pesquisadores ao comparar cuidados prestados à criança morrendo, na Grécia e na China, identificaram que $68 \%$ das enfermeiras que assistiam esses pacientes recorreram à religião para tranqüilizar a angústia resultante desse atendimento $^{(21)}$

Os participantes do estudo revelaram concordância com a concepção de que a morte é uma porta de transição que leva de uma forma de vida a outra, pois a vida é contínua e eterna. Isso é reforçado pela maioria das religiões e escolas espiritualistas que crêem no conceito de imortalidade e indestrutibilidade da alma humana ${ }^{(18)}$.

\section{Sentimentos em relação às diferentes formas de morrer}

A partir dos anos 70 do século passado, a morte foi praticamente institucionalizada porque a evolução tecnológica predominante nos hospitais, principalmente nas unidades de terapia intensiva, criou o hábito de manter as pessoas internadas, mesmo aquelas vítimas de doenças crônicas, fora de possibilidades terapêuticas. É por isso, que atualmente, um grande número de pessoas morrem nos hospitais, ficando isolado de seus entes queridos, permanecendo ao seu lado, apenas dos profissionais de saúde que o assistem.

Os participantes contaram que o investimento terapêutico em crianças internadas na UTIP do HU-USP é semelhante ao realizado nos pacientes da UTIA e de outras UTIs do mundo.

Nesse sentido, Regina demonstrou dificuldades de aceitar a distanásia, que pode ser entendida como o prolongamento inútil e fútil do sofrimento humano que não beneficia o paciente.

Às vezes eu fico revoltada quando eles investem em prematuros!!! Há coisas que eu não aceito de jeito nenhum!! (Regina)

Principalmente os prematuros! Saem aquelas crianças que não enxergam, não escutam, não conseguem andar. Eu falo mesmo, a medicina está muito evoluída mas,... (...) Eles falam que a família quer vivo (Regina).

Eu fico muito triste, se colocando no lugar dela, num futuro que não tem, que vai ser uma pessoa que não vai andar mais, não vai ter qualidade de vida... Eu não gostaria de estar numa situação desta, acho que ninguém (Regina).

Os médicos e os demais profissionais da saúde devem respeitar a importância atribuída pela família e pelo paciente quanto ao que estes entendem por qualidade de vida, considerando não somente o tempo absoluto de sobrevivência dos seus pacientes, mas também a qualidade desta sobrevivência. Para isto, precisam desenvolver pesquisas sobre qualidade de vida, na tentativa de aumentar o domínio e a maturidade quanto às evidências que estas pesquisas demonstram ${ }^{(22)}$.

Nessa perspectiva, os participantes citaram serem favoráveis à ortotanásia, entendida como o morrer com dignidade, sem prolongamento de um lado, e sem abreviação do outro. Poderia ser definida como a boa morte, sem dor, sem sofrimento, incluindo o viver bem.

\section{- Quando idosa, eu me recuso a vir ao hospital. Eu quero ter morte natural!!! (Giovana)}

- Como foi a morte do Sr João. Ele morreu como um passarinho!!! A morte que todo mundo gostaria de ter!!!! (Gustavo)

- Por isso eu também procuro viver bem aqui na terra. (Regina).

Essas palavras vão ao encontro dos achados da pesquisadora, que ouviu em torno de vinte mil pessoas que estiveram à beira da morte, tendo sido declaradas mortas, mas que voltaram a viver. Como ponto comum, essas pessoas afirmaram que a experiência de quase morte havia lhes ensinado que o amor é o verdadeiro significado da vida ${ }^{(23)}$.

\section{SENTIMENTOS EM RELAÇÃO À MORTE E AO PROCESSO DE MORRER}

Os depoimentos advindos do grupo focal assinalam alguns sentimentos comuns em relação à morte, sendo que a aceitação foi o mais destacado entre os citados pelos participantes. No entanto, apreendemos que a aceitação pode ser influenciada pela crença religiosa, pela experiência profissional e/ou também pelo amadurecimento pessoal.

A morte vai ser uma perda sempre. Ficou bem claro, é uma perda!!! (Giovana).

Mas, vejo a morte com uma aceitação passiva. Cada vez eu aceito mais. Viver hoje como se fosse o último dia!!! Não sei que sentimento é este, mas estou mais conformado com isto. Bem mais conformado!!! (Gustavo).

Prá mim a morte não é uma tristeza. Eu encaro como uma coisa boa, eu não acho uma coisa ruim (Regina). 
Eu acredito que a morte são muitas flores, muita luz, muita paz. Por isso, eu também procuro viver bem aqui na terra (Regina).

Na nossa cultura, todos ainda tem medo de falar sobre a morte. Não é fácil falar sobre a morte, mas ela faz parte da nossa realidade. $O$ processo do morrer é que me preocupa muito, pois o indivíduo não tem permissão para passar por este processo com tranqüilidade, pois ele não permite que a morte se aproxime naturalmente (Regina).

Segundo as falas dos participantes, o processo de morrer é gerador de ansiedade porque o profissional não aceita a morte naturalmente, por isso faz inúmeros procedimentos na tentativa de curar o indivíduo. No entanto, os resultados indicam o prolongamento do tempo para o doente morrer, o que acentua o sofrimento do paciente, de sua família e dos profissionais de saúde.

Manter a esperança foi um outro ponto que chamou a atenção nos encontros realizados durante a pesquisa, pois os colaboradores enfatizaram o quanto consideram importante que a família e o paciente cultivem a esperança de que o tratamento será bem sucedido.

O profissional de saúde também considera a esperança uma meta que o auxilia a se fortalecer no trabalho. O significado desvelo da vivências dos participantes, indica que os profissionais de saúde devem alimentar a esperança em relação ao tratamento/melhora do paciente, evitando, assim, aumentar a angústia que pode surgir ao dizer a verdade.

Existe estudo que se refere às frases que indicam falta de esperança: Não há mais nada que possamos fazer; Não existe esperança; Não tenha esperança, tais palavras são frustrantes para os profissionais de saúde e podem causar distanciamento e abandono de investimentos em relação ao paciente $^{(24)}$.

O inconformismo do profissional frente à omissão do outro profissional em relação ao estado do paciente para a família, também foi evidenciado.

\section{Mas eu falei que estava grave!!! E ele chegou e não falou!} (Giovana).

Consideramos bastante delicado o fato de se retirar a esperança ou manter-se a ilusão, assim, sugerimos que a esperança ou desesperança sejam muito bem avaliadas pelos profissionais, no momento de se abordar o paciente e sua família. Consideramos, ainda, que a esperança/desesperança é influenciada pelo amadurecimento e crenças daqueles que receberão a mensagem, resultantes de suas experiências, e também o quanto da mensagem é codificada, pois, às vezes, existe a negação da mensagem por parte do receptor.

O sentimento de onipotência também foi mencionado durante os encontros.
Em relação ao tratamento que a gente vê, o que está segurando é só o remédio! Já está morto há muito tempo! Desligou, foi! (Gustavo)

Os participantes consideram que a tecnologia proporciona ao profissional o adiamento da morte do paciente e que existem profissionais que, por dominarem a tecnologia, se consideram donos da vida conseguindo adiar a morte e deixála chegar quando julgarem conveniente.

Com essa crença os sujeitos do estudo demonstram concordarem com a idéia de que a doença está enraizada na existência humana da mesma forma que a morte, porém, às vezes, as nossas forças são incapazes de combatê-la ${ }^{(25)}$.

A narrativa dos participantes aponta para dimensões que norteiam suas vivências profissionais, que vão além do conhecimento técnico. Embora seja fruto de uma trajetória de vida, o conhecimento compõe e articula elementos da crença cultural, pois torna impossível ao indivíduo despir-se de tudo aquilo em que ele acredita, principalmente nos ambientes onde predominam a dimensão da tecnologia, como nas UTIs. Assim, esses profissionais de enfermagem demonstram que procuram refúgio nos seus valores para suportar um trabalho tão penoso, bem como procuram ampliar o cuidado integrando a ele a dimensão espiritual.

\section{CONSIDERAÇÕES FINAIS}

Devemos salientar que as culturas são dinâmicas, portanto mutáveis, de acordo com os acontecimentos passados, presentes e aqueles que poderão surgir.

A enfermagem lida constantemente com as reações dos pacientes associadas aos problemas de saúde, interessa-se por eles e pelos efeitos da doença na vida deles. Essas reações humanas têm natureza dinâmica e diversificada e vão se modificando na medida em que os pacientes e suas famílias vivenciam diferentes etapas do processo saúde-doença e morte.

É nesse contexto da cultura que consideramos relevantes os estudos que possibilitem aos profissionais de enfermagem desenvolvam o auto-conhecimento e intervenções que auxiliem assistir o paciente e familiares diante do processo de morrer, minimizando o seu próprio sofrimento psíquico e auxiliando no desenvolvimento de estratégia coletivas de enfrentamento.

Considerando que em nossa sociedade o trabalho tende a ser fragmentado pela especialização, burocratização, tendendo ao mecanicismo, impregnado por normas e rotinas, centrado em exigências, às vezes obsoletas ou exageradas que, muitas vezes, impedem o homem de se transformar e de recriar o seu trabalho, é importante apreender e compreender os valores subjacentes às diferentes re- 
presentações sobre o processo de morrer e da morte, com o objetivo de resgatá-las e integrá-las ao modo de ser, pensar, sentir e agir que conferem significado à atuação profissional.

Sob esta ótica, é preciso considerar a necessidade das organizações de saúde adaptarem-se às exigências de uma sociedade que caminha na direção da conquista da cidadania.

\section{REFERÊNCIAS}

1. Santos JL. O que é cultura. 3a ed. São Paulo: Brasiliense; 1989.

2. Uchôa E, Vidal JM. Antropologia médica: elementos conceituais e metodológicos para uma abordagem da saúde e da doença. Cad Saúde Pública. 1994;10(4):497-504.

3. Organización Panamericana de la Salud (OPAS). "Promoción de la salud: una antologia" Ginebra: OPAS; 1996. (Publicación Científica, 557).

4. Hegenberg L. Doença: um estudo filosófico. Rio de Janeiro: FIOCRUZ; 1998.

5. Baraldi S. Sobre o significado da morte e do morrer: identificando similaridades e diferenças no Brasil (São Paulo) e Cuba (Havana) [dissertação] São Paulo: Programa de Pós-graduação em Integração da América Latina, Escola de Enfermagem, Universidade de São Paulo; 1999.

6. Minayo MCS. O desafio do conhecimento: pesquisa qualitativa em saúde. 6 ${ }^{a}$ ed. São Paulo: Hucitec; 1999.

7. Carlini-Cotrim B. Potencialidades da técnica qualitativa do grupo focal em investigação sobre abuso de substâncias. Rev Saúde Pública. 1996;30(3):285-93.

8. Chiesa AM, Ciampone MHT. Princípios gerais para a abordagem de variáveis qualitativas e o emprego da metodologia de grupos focais. In: Criança CM, Antunes MJM, organizadoras. Classificação Internacional das Práticas em Saúde Coletiva: CIPESC/ Brasília: ABEn; 1999. p. 306-24. (Série Didática: Enfermagem no SUS).

9. Py L, Oliveira AC. Humanizando o adeus à vida. Mundo Saúde. 2003;27(2):240-7.

10. Geertz C. A interpretação das culturas. Rio de Janeiro: Livros Técnicos e Científicos; 1989. A religião como sistema cultural; cap. 4, p. 102-42.

11. Boff L. Tempo de transcendência: o ser humano como um prometo infinito. Rio de Janeiro: Sextante; 2000.

12. Langendoen KF, Lanken PN. Dying patients in the Intensive Care Unit: forgoing treatment, maintaining care. Ann Interm Med. 2000;133(11):886-93.
Assim, essas organizações e os profissionais que nelas trabalham precisam desenvolver uma dinâmica de aprendizagem e inovação, melhorando sua capacidade de se adaptar às novas situações que acarretam, muitas vezes dilemas bioéticos, como no caso do prolongamento da vida por meios artificiais. Deve-se procurar desenvolver nessas organizações, espaços para debates a respeito dos conhecimentos e práticas, visando a troca de experiências e o suporte necessário para que os profissionais de saúde acompanhem as transformações, integrando o conhecimento científico em suas práticas, ampliando-as ao âmbito do social e espiritual.

13. Oliveira JFP. Finitude na experiência religiosa. In: Py L. Finitude: uma proposta para reflexão e prática em gerontologia. Rio de Janeiro: NAU; 1999. p. 45-54.

14. Shimizu HE As representações sociais dos trabalhadores de enfermagem não enfermeiros (técnicos e auxiliares de enfermagem) sobre o trabalho em Unidade de Terapia Intensiva em um Hospital-Escola [tese]. São Paulo: Escola de Enfermagem, Universidade de São Paulo; 2000.

15. Elias ACA. Relaxamento mental, imagens mentais e espiritualidade na re-significação da dor simbólica da morte de pacientes terminais [dissertação]. Campinas: Faculdade de Ciências Médicas, Universidade Estadual de Campinas; 2001.

16. Miller S. Depois da vida: desvendando a jornada pós-morte. São Paulo: Sumus; 1997.

17. Gimenez MGG. A passagem entre a vida e a morte: uma perspectiva psico-espiritual em cuidados paliativos. Mundo Saúde. $2003 ; 27(1): 153-8$.

18. Hoffmann L. A morte na infância e sua representação para o médico: reflexões sobre a prática pediátrica em diferentes contextos. Cad Saúde Pública. 1993;9(3):364-74.

19. Kübler-Ross E. Sobre a morte e o morrer. São Paulo: Martins Fontes; 1996.

20. Papadatou D, Martinson IM, Chung PM. Caring for dying children: a comparative study of nurses' experiences in Greece and Hong Kong. Cancer Nurs. 2001;24(5):402-12.

21. Froner YA. Os símbolos da morte e a morte simbólica: um estudo do imaginário na arte colonial mineira [dissertação]. São Paulo: Faculdade de Filosofia, Letras, Ciências Sociais e História, Universidade de São Paulo; 1994.

22. Kübler-Ross E. A roda da vida. Rio de Janeiro: Sextante; 1998.

23. Norton SA, Talerico KA. Facilitating end-of-life decisionmaking: strategies for communicating and assessing. J Gerontol Nurs. 2000;26(9):6-13.

24. Dethlefsen T, Dahlke R. A doença como caminho. São Paulo: Cultrix; 1983. A doença e os sintomas; p. 11-9. 